\section{Halt reef destruction in South China Sea}

China's land reclamation in the South China Sea has raised geopolitical concerns (see go.nature.com/tmrpih). It is also destroying coral reefs on a large scale - together with their fragile ecosystems.

This loss of reef habitat is estimated from high-resolution satellite imagery to be about 1,400 hectares so far in the Spratly Islands (http://amti.csis. org/island-tracker). The reefs are among the most biologically diverse on the planet. They are home to threatened turtle and bird species, a crucial stopover for migratory birds, and a source of larvae for the South China Sea's overexploited coastal fisheries. Further dredging will kill nearby sediment-dwelling communities and sea-grass nursery habitats that take up carbon.

The global scientific, conservation and legal communities must unite to halt this destruction. Reef loss can be publicly monitored with Google Earth imagery and tools, enabling international governing bodies to enforce China's obligations under international law to protect and sustainably manage their reefs (see go.nature.com/wdzf9k). And funding should be fast-tracked for the proposed protective Spratly Islands Marine Peace Park (J.W. McManus et al. Ocean Dev. Int. Law 41, 270-280; 2010).

Elizabeth M. P. Madin

Macquarie University, Sydney, Australia.

dr.elizabeth.madin@gmail.com

\section{STEM teaching: medicine in Europe}

The innovations to science, technology, engineering and mathematics (STEM) education you recommend (Nature 523, 272-274 and 282-284; 2015) have already had a major impact on the teaching of medicine in Europe over the past 15 years, especially in the United
Kingdom and the Netherlands. These have been inspired by initiatives such as Best Evidence Medical Education (BEME; www.bemecollaboration.org) and ASPIRE (www.aspire-toexcellence.org), both run by the Association for Medical Education in Europe.

There have been 32 systematic reviews examining the literature to determine which teaching methods work and why, and how they could be made more effective - including three highly cited BEME reviews (S. A. Azer Acad. Med. 90, 1147-1161; 2015). The ASPIRE initiative has ensured that teaching is now recognized internationally alongside excellence in research (see R. M. Harden and D. Wilkinson Med. Teach. 33, 95-96; 2011).

There has also been a drastic change in performance assessment of medical students. This no longer relies on regurgitating facts. Examples include the objective structured clinical examination, workplace-based assessments and entrustable professional activities, which emphasize the importance of feedback in monitoring and supporting undergraduate learning. Trudie E. Roberts University of Leeds, UK; and Association for Medical Education in Europe, Dundee, UK

Ronald M. Harden Association for Medical Education in Europe, Dundee, UK.

t.e.roberts@leeds.ac.uk

\section{STEM teaching: the need for wider skills}

Now more than ever, students of science, technology, engineering and mathematics (STEM) need to develop skills for realworld problem solving (see Nature 523, 272-274; 2015). These include leadership, collaboration, communication and interdisciplinary thinking all sought after by companies and organizations that must compete in today's global economy.

In the Integrated

Concentration in Science (iCons)

Program I have launched at the

University of Massachusetts

Amherst (see www.cns.umass. edu/icons-program), STEM students explore the part that science can play in tackling societal challenges such as cancer, climate change and clean energy. For example, one iCons team identified electrical energy storage as a crucial societal need, which motivated them to design and perform an original investigation on the efficient electrolysis of water. Such innovative educational experiences generate new categories of learning that broaden the meaning of student success - important both for students and for the future. Scott Auerbach University of Massachusetts Amherst, USA. auerbach@chem.umass.edu

\section{Funders must not coerce scientists}

The reported complicity of the American Psychological Association (APA) in the 'enhanced interrogation' programme of the US Department of Defense (DOD) represents improper exploitation by the DOD of its relationship with the APA in pursuit of its own objectives, distorting scientific ethics and practices in the process (see Nature 523, 255; 2015). The scientific community as a whole could learn from the mechanisms that the DOD used to influence the APA, as reported in an independent review (go.nature.com/4vpdob).

Historically, similarly inappropriate relationships have sometimes developed between granting agencies and scientists (see, for example, S. Reverby Examining Tuskegee (Univ. North Carolina Press, 2009) and Nature 467, 645; 2010). Scientists' alignment with institutional preferences is often a force for good, but vigilance is needed to prevent erosion of ethical or evidential standards.

Institutional coercion such as that revealed in the report is disastrous for the public perception and integrity of science. The moral force of research standards is weakened if they are subject to political concerns.

We all need to address this potential for abuse without impeding the normal functioning of scientists and their granting institutions. For example, negotiations on ethics and research practices between institutions could be overseen to ensure good-faith participation and eliminate any back-door dealing. Such regulatory authority could be absorbed by existing bodies such as the US Federal Inspectors General. Cole Helsell University of California, San Francisco, USA. cole.helsell@ucsf.edu

\section{India's inspiring former president}

A.P. J. Abdul Kalam (1931-2015) was the first great scientist to become president of India (see Nature India go.nature.com/ x8rltb). He died on 27 July while delivering a lecture on 'The liveable planet' to students at the Indian Institute of Management in Shillong.

Dubbed the 'missile man' because of his pioneering years as head of India's missile programme, he was a big supporter of fundamental and applied science in the country. He was a favourite among students, igniting the minds of primary-school children and $\mathrm{PhD}$ students alike about science through his passion and approachability, patience and simplicity.

Bhaswati Chatterjee National Institute of Pharmaceutical Education and Research, Hyderabad, India. Suman S. Thakur Centre for Cellular \& Molecular Biology, Hyderabad, India.

sst@ccmb.res.in 